\title{
Endoscopic Management of Peptic Ulcer Bleeding: Recent Advances
}

\author{
Philip WY Chiu \\ Department of Surgery, Institute of Digestive Disease, The Chinese University of Hong Kong, Prince of Wales Hospital, Hong Kong, China
}

Bleeding peptic ulcers remained as one of the commonest causes of hospitalization worldwide. While endoscopic hemostasis serves as primary treatment for bleeding ulcers, rebleeding after endoscopic hemostasis becomes more and more difficult to manage as patients are usually poor surgical candidates with multiple comorbidities. Recent advances in management of bleeding peptic ulcers aimed to further reduce the rate of rebleeding through-(1) identification of high risk patients for rebleeding and mortality; (2) improvement in primary endoscopic hemostasis and; (3) prophylactic angiographic embolization of major arteries. The technique and clinical evidences for these approaches will be reviewed in the current article. Clin Endosc 2019;52:416-418

Key Words: Bleeding peptic ulcer; Endoscopy; Transarterial embolization

\section{INTRODUCTION}

Bleeding peptic ulcers remain the most common cause of upper gastrointestinal bleeding worldwide. ${ }^{1}$ Over the past 20 years, mortality resulting from bleeding peptic ulcers had significantly decreased through researches on primary endoscopic hemostasis, improvement in pre- and post-endoscopic management, as well as identification of patients at a risk of catastrophic events-for close observation and focused intensive management. ${ }^{2}$ However, the risks of patients with bleeding peptic ulcers had significantly increased owing to the aging population with multiple comorbidities, as well as because of the increasing use of aspirin and non-steroidal anti-inflammatory drugs. ${ }^{3}$ Patients with peptic ulcers of high rebleeding risk are generally poor surgical candidates. ${ }^{4}$ Recent developments in endoscopic therapy have aimed to further

Received: October 13, 2018 Revised: May 28, 2019

Accepted: May 30, 2019

Correspondence: Philip WY Chiu

Department of Surgery, Institute of Digestive Disease, The Chinese University of Hong Kong, Prince of Wales Hospital, 30-32 Ngan Shing St, Sha Tin, Hong Kong, China

Tel: +852-3505-2956, Fax: +852-9125-2907, E-mail: philipchiu@surgery.cuhk. edu.hk

ORCID: https://orcid.org/0000-0001-9292-112X

(c) This is an Open Access article distributed under the terms of the Creative Commons Attribution Non-Commercial License (http://creativecommons.org/ licenses/by-nc/3.0) which permits unrestricted non-commercial use, distribution, and reproduction in any medium, provided the original work is properly cited. improve the clinical outcomes of patients with bleeding peptic ulcers in two areas: (1) identification of high-risk patients with prediction scores and selection of patients for pre-emptive interventions and (2) improvement of primary endoscopic therapy through innovative technologies.

\section{IDENTIFICATION OF HIGH-RISK PATIENTS FOR REBLEEDING}

In a review, we summarized the clinical studies on prediction models for clinical outcomes in upper gastrointestinal bleeding. ${ }^{5}$ Most studies showed that the presence of shock at presentation, actively bleeding ulcers, size of the ulcer, and ulcer location at the posterior duodenal bulb and high lesser curvature were significant predictive factors of rebleeding. These factors are typically related to the severity of ulcer bleeding, as well as the anatomical location and size of the ulcer. Apparently, strategies to improve primary endoscopic hemostasis would contribute to lowering the risk of rebleeding-an important predictor of mortality. ${ }^{6}$

\section{INNOVATIVE THERAPY FOR PRIMARY ENDOSCOPIC HEMOSTASIS}

A systematic review and meta-analysis demonstrated that 
combination therapy had higher success in achieving secure primary hemostasis than injection therapy alone. ${ }^{7}$ Generally, injection of epinephrine achieves hemostasis for bleeding peptic ulcers through local tamponade and pharmacological effects. ${ }^{8}$ However, recurrent hemorrhage typically occurs in the first $72 \mathrm{~h}$ after endoscopic hemostasis, when these effects have faded. The application of a second treatment, either thermal or mechanical therapy, achieves hemostasis with a prolonged effect when targeting the bleeding arteriole. ${ }^{9,10}$ Endoclips are applied to or around the bleeding arteriole to achieve hemostasis through the formation of clot upon clipping on the ulcer base. Although effective as a primary therapy, hemoclips tend to dislodge in $48-72 \mathrm{~h}$ after application, which could lead to further bleeding. ${ }^{11}$

A scheduled second endoscopy is performed to identify patients with persistent stigmata of recent hemorrhage, and retreatment is performed at $16-24 \mathrm{~h}$ after the initial endoscopic hemostasis. ${ }^{12}$ In a randomized trial, our group demonstrated that performing a scheduled second endoscopy significantly reduced the rate of ulcer rebleeding from $13.8 \%$ to $5 \%{ }^{13}$ There was no difference in the need for surgery and in mortality. Lau et al. conducted a prospective randomized trial comparing intravenous infusion of proton pump inhibitors (PPIs) against placebo for peptic ulcer bleeding. ${ }^{14}$ In 240 patients with bleeding peptic ulcers after endoscopic hemostasis, highdose PPI infusion significantly reduced the rebleeding rate $(6.7 \%$ vs. $22.5 \%)$. There was a trend toward a reduction in the need for surgery. Hence, either scheduled second endoscopy or PPI infusion could reduce rebleeding after endoscopic therapy. We then compared the two strategies for the prevention of peptic ulcer rebleeding in another randomized trial. ${ }^{15}$ PPI infusion was found to achieve a similar effect in preventing ulcer rebleeding to that of scheduled second endoscopy. The recent consensus on non-variceal upper gastrointestinal bleeding does not recommend routine second-look endoscopy when PPI infusion is prescribed after endoscopic therapy. ${ }^{16}$

There are novel therapeutic options for achieving better hemostasis during primary endoscopy for ulcer bleeding.
The application of the over-the-scope clip (OTSC) achieves secure hemostasis, as the clip tends to stay in the ulcer site for a longer period. Chan et al. reported that in a cohort of nine patients with upper gastrointestinal bleeding, hemostasis was achieved with OTSC. ${ }^{17}$ The median ulcer size was $25 \mathrm{~mm}$, and the technical success rate was $100 \%$ with a clinical success rate for hemostasis of $77.8 \%$. The mean time for OTSC to remain in situ over the ulcer crater was 28 days (0-42 days). Schmidt et al. reported a retrospective comparative study between the use of standard therapy and OTSC for the management of rebleeding after primary endoscopic hemostasis in 66 patients. ${ }^{18}$ The group treated by OTSC had significantly lower rates of rebleeding than the group treated with standard therapy $(6.0 \%$ vs. $42.4 \%, p=0.001$ ).

Our group had pioneered the development of an endoscopic suturing device-Eagle Claw. In preclinical porcine model experiments, Eagle Claw was demonstrated to be effective in achieving hemostasis for large-sized massively bleeding ulcers. ${ }^{19}$ Eagle Claw was translated into Apollo Overstitch for clinical application. We reported our experience in using Overstitch for complete closure of bleeding ulcers to achieve a similar effect to that of surgical ulcer exclusion. ${ }^{20}$ Without exposure of the ulcer crater to intragastric acid, the risk of rebleeding would be minimal. To achieve closure of a largesized ulcer, suture should be applied to the ulcer edges in a figure-of-eight manner. Generally, two to three sutures would be able to completely close an ulcer with a size of $20-30 \mathrm{~mm}$ (Fig. 1).

\section{PROPHYLACTIC ANGIOGRAPHIC EMBOLIZATION FOR BLEEDING PEPTIC ULCERS}

With advances in endoscopic management, the need for surgery in bleeding peptic ulcers has significantly decreased. However, in a previous study, patients undergoing salvage surgery are usually high-risk candidates for surgery with multiple
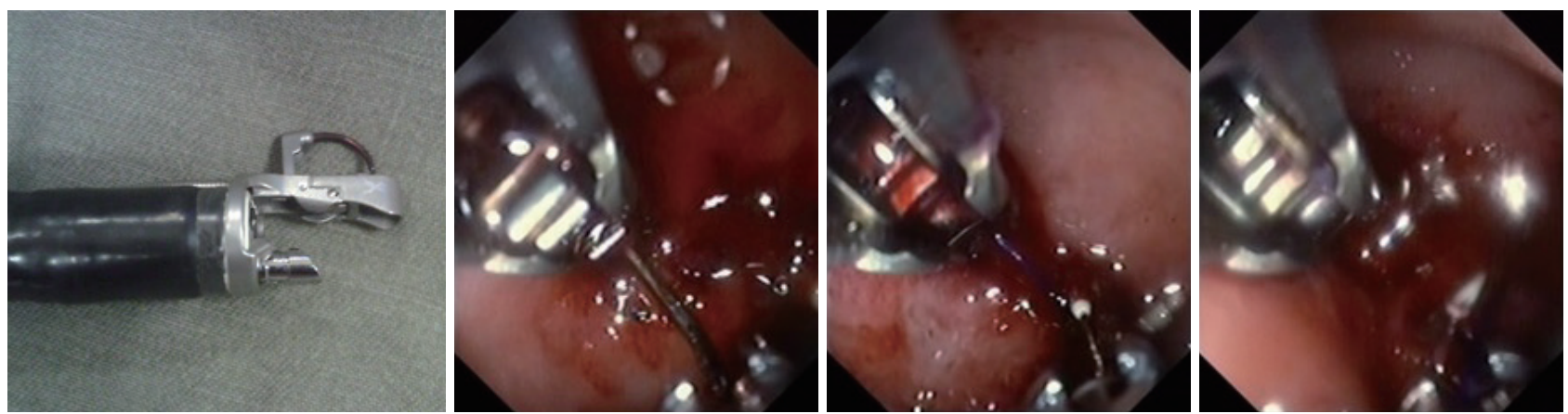

Fig. 1. Overstitch endoscopic suturing device and endoscopic hemostasis of a bleeding duodenal ulcer with Overstitch. 
comorbidities and advanced age. ${ }^{4}$ Angiographic embolization aims to control ulcer rebleeding through blockage of the major feeding artery to the ulcer. Ulcers located at the posterior duodenal bulb carry a higher risk of rebleeding, as the gastroduodenal artery is anatomically located near the posterior duodenal wall. Our group reviewed our experience of angiographic embolization for the management of peptic ulcer rebleeding. ${ }^{21}$ A total of 32 patients who underwent transarterial embolization were compared with 56 patients who underwent surgery. Although more rebleeding occurred in patients who underwent embolization than in those who underwent surgery, more complications occurred in the surgical group. There was no difference in the 30-day mortality and hospital stay. Lau et al. conducted a prospective randomized trial comparing angiographic embolization with standard therapy for the prevention of rebleeding after therapeutic endoscopy. ${ }^{22} \mathrm{~A}$ total of 241 patients were randomized to either angiographic embolization $(n=118)$ or standard treatment $(n=123)$. Among them, $12(10.2 \%)$ patients in the embolization group and 14 (11.4\%) patients in the standard treatment group developed rebleeding (hazard ratio, 1.14; 95\% confidence interval, $0.53-$ 2.46; $p=0.745)$. In a post hoc analysis, embolization reduced recurrent bleeding only in patients with ulcers $\geq 15 \mathrm{~mm}$ in size (2 [4.5\%] vs. 12 [23.1\%], $p=0.027)$. Hence, for large-sized, highrisk ulcers, prophylactic angiographic embolization will help prevent ulcer rebleeding.

\section{CONCLUSIONS}

Endoscopic hemostasis is the current primary treatment for bleeding peptic ulcers, and patients who experience rebleeding have significant mortality risks. Large-sized ulcers and ulcers located at the posterior duodenal bulb are important predictive factors of rebleeding. Novel endoscopic therapies including OTSC and Overstitch have significantly improved the security of primary endoscopic hemostasis and have reduced rebleeding. Preemptive angiographic embolization has reduced rebleeding for ulcers $>15 \mathrm{~mm}$ in size and should be considered for patients with advanced age and a high surgical risk.

\section{Conflicts of Interest}

The author has no financial conflicts of interest.

\section{REFERENCES}

1. Lau JY, Sung J, Hill C, Henderson C, Howden CW, Metz DC. Systematic review of the epidemiology of complicated peptic ulcer disease: incidence, recurrence, risk factors and mortality. Digestion 2011;84:102-113.

2. Quan S, Frolkis A, Milne K, et al. Upper-gastrointestinal bleeding secondary to peptic ulcer disease: incidence and outcomes. World J Gastroenterol 2014;20:17568-17577.

3. Melcarne L, García-Iglesias P, Calvet X. Management of NSAID-associated peptic ulcer disease. Expert Rev Gastroenterol Hepatol 2016;10:723733.

4. Chiu PW, Ng EK, Wong SK, et al. Surgical salvage of bleeding peptic ulcers after failed therapeutic endoscopy. Dig Surg 2009;26:243-248.

5. Chiu PW, Ng EK. Predicting poor outcome from acute upper gastrointestinal hemorrhage. Gastroenterol Clin North Am 2009;38:215-230.

6. Chiu PW, Chan FK. Upper gastrointestinal bleeding: risk scores and clinical judgment in predicting outcomes of UGIB. Nat Rev Gastroenterol Hepatol 2014;11:399-401.

7. Sung JJ, Tsoi KK, Lai LH, Wu JC, Lau JY. Endoscopic clipping versus injection and thermo-coagulation in the treatment of non-variceal upper gastrointestinal bleeding: a meta-analysis. Gut 2007;56:1364-1373.

8. Chung SC, Leung JW, Steele RJ, Crofts TJ, Li AK. Endoscopic injection of adrenaline for actively bleeding ulcers: a randomised trial. Br Med J (Clin Res Ed) 1988;296:1631-1633.

9. Chung SC, Leung JW, Sung JY, Lo KK, Li AK. Injection or heat probe for bleeding ulcer. Gastroenterology 1991;100:33-37.

10. Lin HJ, Hsieh YH, Tseng GY, Perng CL, Chang FY, Lee SD. A prospective, randomized trial of endoscopic hemoclip versus heater probe thermocoagulation for peptic ulcer bleeding. Am J Gastroenterol 2002;97:2250-2254.

11. Jensen DM, Machicado GA. Hemoclipping of chronic canine ulcers: a randomized, prospective study of initial deployment success, clip retention rates, and ulcer healing. Gastrointest Endosc 2009;70:969-975.

12. Saeed ZA. Second thoughts about second-look endoscopy for ulcer bleeding? Endoscopy 1998;30:650-652.

13. Chiu PW, Lam CY, Lee SW, et al. Effect of scheduled second therapeutic endoscopy on peptic ulcer rebleeding: a prospective randomised trial. Gut 2003;52:1403-1407.

14. Lau JY, Sung JJ, Lee KK, et al. Effect of intravenous omeprazole on recurrent bleeding after endoscopic treatment of bleeding peptic ulcers. $\mathrm{N}$ Engl J Med 2000;343:310-316.

15. Chiu PW, Joeng HK, Choi CL, et al. High-dose omeprazole infusion compared with scheduled second-look endoscopy for prevention of peptic ulcer rebleeding: a randomized controlled trial. Endoscopy 2016;48:717-722.

16. Sung JJ, Chan FK, Chen M, et al. Asia-Pacific Working Group consensus on non-variceal upper gastrointestinal bleeding. Gut 2011;60:1170-1177.

17. Chan SM, Chiu PW, Teoh AY, Lau JY. Use of the over-the-scope clip for treatment of refractory upper gastrointestinal bleeding: a case series. Endoscopy 2014;46:428-431.

18. Schmidt A, Gölder S, Goetz M, et al. Over-the-scope clips are more effective than standard endoscopic therapy for patients with recurrent bleeding of peptic ulcers. Gastroenterology 2018;155:674-686.e6.

19. Chiu PW, Hu B, Lau JY, Sun LC, Sung JJ, Chung SS. Endoscopic plication of massively bleeding peptic ulcer by using the Eagle Claw VII device: a feasibility study in a porcine model. Gastrointest Endosc 2006;63:681-685

20. Chiu PW, Chan FK, Lau JY. Endoscopic suturing for ulcer exclusion in patients with massively bleeding large gastric ulcer. Gastroenterology 2015;149:29-30.

21. Wong TC, Wong KT, Chiu PW, et al. A comparison of angiographic embolization with surgery after failed endoscopic hemostasis to bleeding peptic ulcers. Gastrointest Endosc 2011;73:900-908.

22. Lau JYW, Pittayanon R, Wong KT, et al. Prophylactic angiographic embolisation after endoscopic control of bleeding to high-risk peptic ulcers: a randomised controlled trial. Gut 2019;68:796-803. 